This item was submitted to Loughborough's Research Repository by the author.

Items in Figshare are protected by copyright, with all rights reserved, unless otherwise indicated.

\title{
Physical complexity to model morphological changes at a natural channel bend
}

PLEASE CITE THE PUBLISHED VERSION

http://dx.doi.org/10.1002/2015WR017917

\section{PUBLISHER}

(C) American Geophysical Union

\section{VERSION}

VoR (Version of Record)

\section{PUBLISHER STATEMENT}

This work is made available according to the conditions of the Creative Commons Attribution-NonCommercialNoDerivatives 4.0 International (CC BY-NC-ND 4.0) licence. Full details of this licence are available at: https://creativecommons.org/licenses/by-nc-nd/4.0/

\section{LICENCE}

CC BY-NC-ND 4.0

\section{REPOSITORY RECORD}

Guan, Mingfu, N.G. Wright, P.A. Sleigh, Sangaralingam Ahilan, and R. Lamb. 2019. "Physical Complexity to Model Morphological Changes at a Natural Channel Bend". figshare. https://hdl.handle.net/2134/22826. 


\section{Water Resources Research}

\section{RESEARCH ARTICLE \\ 10.1002/2015WR017917 \\ Physical complexity to model morphological changes at a natural channel bend}

Key Points:

- We developed a 2-D depth-averaged model for morphological changes at natural bends

- A secondary flow correction plays an crucial role in bar deformation at a bend

- Parameterization of grain size should be given a priority for morphological modeling

Correspondence to:

M. Guan,

mingfu.guan@hotmail.com

\section{Citation:}

Guan, M., N. G. Wright, P. A. Sleigh, S. Ahilan, and R. Lamb (2016), Physical complexity to model morphological changes at a natural channel bend, Water Resour. Res., 52, 6348-6364, doi:10.1002/2015WR017917.

Received 30 JUL 2015 Accepted 1 AUG 2016 Accepted article online 5 AUG 2016 Published online 18 AUG 2016

\author{
M. Guan ${ }^{1,2}$, N. G. Wright ${ }^{3}$, P. A. Sleigh ${ }^{1}$, S. Ahilan ${ }^{1}$, and R. Lamb ${ }^{4,5}$ \\ ${ }^{1}$ School of Civil Engineering, University of Leeds, Leeds, UK, ${ }^{2}$ Department of Geography, Loughborough University, \\ Loughborough, UK, ${ }^{3}$ Faculty of Technology, De Montfort University, Leicester, UK, ${ }^{4}$ JBA Trust, Skipton, UK, ${ }^{5}$ Lancaster \\ Environment Centre, Lancaster University, Lancaster, UK
}

\begin{abstract}
This study developed a two-dimensional (2-D) depth-averaged model for morphological changes at natural bends by including a secondary flow correction. The model was tested in two laboratory-scale events. A field study was further adopted to demonstrate the capability of the model in predicting bed deformation at natural bends. Further, a series of scenarios with different setups of sediment-related parameters were tested to explore the possibility of a 2-D model to simulate morphological changes at a natural bend, and to investigate how much physical complexity is needed for reliable modeling. The results suggest that a 2-D depth-averaged model can reconstruct the hydrodynamic and morphological features at a bend reasonably provided that the model addresses a secondary flow correction, and reasonably parameterize grain-sizes within a channel in a pragmatic way. The factors, such as sediment transport formula and roughness height, have relatively less significance on the bed change pattern at a bend. The study reveals that the secondary flow effect and grain-size parameterization should be given a first priority among other parameters when modeling bed deformation at a natural bend using a 2-D model.
\end{abstract}

\section{Introduction}

Morphological changes commonly occur with flows in natural systems over period of time and changes are more produced during floods. In recent years, increasing attention has been paid to numerical modeling of river hydrodynamics and morphodynamics, and a large number of computational models have been developed [Abad et al., 2008; Guan et al., 2015a; Li and Duffy, 2011; Wu, 2004]. However, in contrast to straight channels, channel bends demonstrate much more complex flow features due to the presence of helical (secondary) flows [Blanckaert, 2015; De Vriend, 1977; Johannesson and Parker, 1989; Odgaard, 1986; Song et al., 2012]. Consequently, there is a high demand to deal with such flow features to reasonably simulate bed formation around channel bends. Three-dimensional (3-D) models can be an option to predict bed deformation in channel bends, because a 3-D model can give more detailed computation of the water flow field [Bui and Rutschmann, 2010; Fischer-Antze et al., 2008; Khosronejad et al., 2007; Wu et al., 2000]. Yet, the disadvantage of using a fully 3-D model is that it costs over an order of magnitude longer in computational time than a 2-D model. More importantly, the 3-D aspects of the physical sediment-related knowledge are not well understood and established yet. Therefore, a 2-D model appears to be more attractive for engineering application and analysis. Most of the existing 2-D models for flow and bed deformation neglect 3-D flow features by integrating the flow in depth. This leads to under or overestimate hydrodynamics and morphodynamics at bends to a certain extent. Accordingly, there is a necessity to reasonably depict 3-D flow feature at bends. Some studies have reported that it is a possible to model the secondary flow effect in 2-D hydrodynamic model by incorporating a dispersion term [Ghamry and Steffler, 2002; Song et al., 2012]. The inclusion of the secondary flow effect in 2-D hydrodynamic model can lead to reasonable predictions of the velocities at bends characterized by a higher value at outer bank and a lower value at inner bank. Further there are some, but rare, examples of depth-averaged flow models with suspended load or bed load or both considering a secondary flow [e.g., Begnudelli et al., 2010; Duan and Nanda, 2006; Finnie et al., 1999; Iwasaki et al., 2016; Langendoen et al., 2015; Nicholas, 2013; Wang et al., 2014]. These studies emphasized the effects of a secondary flow on hydrodynamics and bend evolution through laboratory tests. Verhaar et al. [2008] reported that the effective test for the accuracy of a morphodynamic model would be though 
comparison against a morphological survey of a river. However, field data sets in a natural river are quite scarce, leaving in field testing of models to be challenging.

Moreover, unlike flood modeling over a fixed riverbed, flow modeling with river morphology contains many empirical formulas and sediment-related parameters which might significantly affect simulation of bed deformation at bends. Some studies have pointed out that sediment composition impacts sediment transport and yield, thereby greatly affecting channel morphology [Waters and Curran, 2015]. However, to spatially estimate grain sizes in reality is rather arbitrary and likewise a difficult work because of the complexity of real riverbeds. Also, the sediment transport formula is a vital parameter when calculating bed changes, but unfortunately, all the existing functions have limited scope of application because of the empirically derived nature of them all [e.g., Cheng, 2002; Meyer-Peter and Müller, 1948; van Rijn, 1984; Wong and Parker, 2006]. The secondary flow effects have been proven to affect both hydrodynamics and morphodynamics at a flume bend. However, at a natural bend, important questions to ask are: how does secondary flow affect morphological changes and what is the importance of secondary flows on bed deformation compared to other sediment-related factors such as the method used to calculate bed shear stress? These questions are far from being answered in existing studies. Moreover, some studies [e.g., Bohorquez et al., 2013; Palmsten et al., 2015] reported that bed form as ripples and dunes in river bends can increase the effective roughness height and total shear stress at both lab and field scales. It should be noted that in turn this can further affect hydrodynamics and morphodynamics at the bend.

In this study, built on our previous model [Guan et al., 2014], a nonequilibrium sediment transport model based on adaption length concept was developed for hydrodynamics and morphodynamics at channel bends and tested in laboratory-scale events with a short-time scale. The significance of a secondary flow on the geomorphological processes was explored based on field survey data set. Specifically, the research questions we are aiming to address are: (1) what role does a secondary flow play in simulating hydrodynamics and morphodynamics at natural bends?, (2) How does the input of sediment-related parameters affect the modeled morphodynamics?, (3) Is it possible to reliably model morphodynamics at natural channel bends using a 2-D model?, and (4) How much physical complexity is needed?

\section{Model Development}

\subsection{Depth-Averaged Flow and Sediment Transport Model}

Building on the depth-averaged 2-D flow and sediment transport model in the previous work [Guan et al., 2014, 2015b, 2016], this study further incorporates turbulent terms and dispersion terms representing the effects of a secondary flow. The original hydromorphodynamic model is detailed in Guan et al. [2014]. The governing equations are written in a conservative form as:

$$
\frac{\partial \mathbf{U}}{\partial t}+\frac{\partial \mathbf{E}}{\partial x}+\frac{\partial \mathbf{F}}{\partial y}=\frac{\partial \tilde{\mathbf{E}}}{\partial x}+\frac{\partial \tilde{\mathbf{F}}}{\partial y}+\mathbf{S}
$$

where

$$
\begin{gathered}
\mathbf{U}=\left[\begin{array}{c}
\eta \\
h u \\
h v
\end{array}\right], \mathbf{E}=\left[\begin{array}{c}
h u \\
h u^{2}+\frac{1}{2} g h^{2} \\
h u v
\end{array}\right], \mathbf{F}=\left[\begin{array}{c}
h v \\
h u v \\
h v^{2}+\frac{1}{2} g h^{2}
\end{array}\right], \tilde{\mathbf{E}}=\left[\begin{array}{c}
0 \\
h\left(T_{x x}+D_{x x}\right) \\
h\left(T_{x y}+D_{x y}\right)
\end{array}\right], \tilde{\mathbf{F}}=\left[\begin{array}{c}
0 \\
h\left(T_{y x}+D_{y x}\right) \\
h\left(T_{y y}+D_{y y}\right)
\end{array}\right] \\
\mathbf{S}=\left[\begin{array}{c}
g h\left(-\frac{\partial z_{b}}{\partial x}-S_{f x}\right)+\frac{\Delta \rho u}{\rho} \frac{\partial z_{b}}{\partial t}[\alpha(1-p)-c]-\frac{\Delta \rho g h^{2}}{2 \rho} \frac{\partial C}{\partial x}-S_{a} \\
g h\left(-\frac{\partial z_{b}}{\partial y}-S_{f y}\right)+\frac{\Delta \rho v}{\rho} \frac{\partial z_{b}}{\partial t}[\alpha(1-p)-c]-\frac{\Delta \rho g h^{2}}{2 \rho} \frac{\partial C}{\partial y}-S_{b}
\end{array}\right]
\end{gathered}
$$

where $\mathbf{U}$ is the vector of conserved variables; $\mathbf{E}, \mathbf{F}$ are the flux vectors of the flow in $x$ and $y$ direction, respectively, $\tilde{\mathbf{E}}, \tilde{\mathbf{F}}$ are the turbulent and dispersion vectors in $x$ and $y$ direction, and $\mathbf{S}$ is the vector of source terms; $h=$ flow depth; $z_{b}=$ bed elevation; $\eta=$ water surface; $u, v=$ the $x$ and $y$ components of depth-averaged flow velocity, respectively; $T_{x x}, T_{x y}, T_{y x}$ and $T_{y y}$ are the depth-averaged turbulent stresses; $D_{x x}, D_{x y}, D_{y x}$ and 
$D_{y y}$ are the dispersion terms due to the effect of secondary flow; $p=$ sediment porosity; $c=$ total volumetric concentration; $\rho_{s}, \rho_{w}=$ densities of sediment and water respectively; $\Delta \rho=\rho_{s}-\rho_{w} ; \rho=$ density of flowsediment mixture; $S_{f x}, S_{f y}$ are frictional slopes in $x$ and $y$ direction; $\alpha=u_{s} / u=$ sediment-to-flow velocity ratio determined by equation [Greimann et al., 2008]; $S_{a}, S_{d}$ are additional terms related to the velocity ratio defined by Guan et al. [2014].

$$
\begin{aligned}
& S_{a}=\frac{\Delta \rho u}{\rho}(1-\alpha)[c \nabla \cdot(h \mathbf{V})-(h \mathbf{V}) \nabla \cdot \mathbf{C}] \\
& S_{b}=\frac{\Delta \rho v}{\rho}(1-\alpha)[c \nabla \cdot(h \mathbf{V})-(h \mathbf{V}) \nabla \cdot \mathbf{C}]
\end{aligned}
$$

where $\nabla=\vec{i}(\partial / \partial x)+\vec{j}(\partial / \partial y)$; $\mathbf{C}$ is the sediment concentration vector defined by $\mathbf{C}=c(\vec{i}+\vec{j}) ; \mathbf{V}$ is the velocity vector defined by $\mathbf{V}=u \vec{i}+v \vec{j}$.

The governing equation of the ith size class is written considering the velocity ratio $\alpha$ by

$$
\frac{\partial h c_{i}}{\partial t}+\frac{\alpha \partial h u c_{i}}{\partial x}+\frac{\alpha \partial h v c_{i}}{\partial y}=-\frac{\alpha\left(q_{b i}-F_{i} q_{b * i}\right)}{L_{i}}
$$

where $c_{i}=$ volumetric bed load concentration of the ith size class; $q_{b i}=h \bar{U} c_{i}=$ real sediment transport rate of the $i$ th fraction; $\bar{U}=\sqrt{u^{2}+v^{2}}$ is the depth-averaged velocity; $q_{b^{*} i}=$ sediment transport capacity of the $i$ th fraction; $F_{i}$ represents the proportion of $i$ th grain-size fraction in total moving sediment. The updating of $F_{i}$ at each time step is conducted using the approach presented by $W u$ [2004]. In equation (4), $L_{i}$ is the nonequilibrium adaptation length of sediment transport of the ith fraction, which is estimated using the formula in Guan et al. [2014]. The bed load transport vector $\left(h u c_{i}, h v c_{i}\right)$ in the mass conservation equation (equation (4)) reflects the velocity vector, which is modified in the hydrodynamic equations (1)-(3) according to secondary flow effects. No bed slope correction is involved in computing the bed load transport. Turbulence and dispersion terms may have effects on the transport of sediment concentration; however, since the model is a bed load-dominant sheet flow model, these terms were not considered in this study.

Sediment transport formulae are commonly regarded as having poor accuracy, therefore, three different formulae are used here to demonstrate its sensitivity on modeled results, including the commonly used equations Meyer-Peter and Müller [1948] (MPM) and Cheng [2002], as well as the equation by Wilcock and Crowe [2003] (WC2003) which was based on data derived from beds of heterogeneous sediment. The transport capacity is expressed by

$$
q_{b * i}=\varphi \sqrt{g\left(\rho_{s} / \rho_{w}-1\right) d_{i}^{3}}
$$

where

$$
\begin{gathered}
\varphi=8\left(\theta_{i}-\theta_{c r, i}\right)^{1.5} \text { for MPM; } \\
\varphi=13 \theta_{i}^{1.5} \exp \left(-0.05 / \theta_{i}^{1.5}\right) \text { for Cheng; } \\
\varphi=\left\{\begin{array}{c}
0.002\left(\theta_{i} / \theta_{r i}\right)^{7.5} \theta_{i} / \theta_{r i}<1.35 \\
14\left(1-\frac{0.894}{\sqrt{\theta_{i} / \theta_{r i}}}\right)^{4.5} \theta_{i} / \theta_{r i} \geq 1.35
\end{array}\right. \text { for WC2003; }
\end{gathered}
$$

where, $\theta_{i}$ is the dimensionless bed shear stress of $i$ th fraction; $\theta_{c r i}$ is critical dimensionless bed shear stress of $i$ th fraction; and $\theta_{r i}$ is the reference dimensionless bed shear stress defined by Wilcock and Crowe [2003] as

$$
\begin{gathered}
\theta_{r i}=\theta_{r, d 50}\left(\frac{d_{i}}{d_{50}}\right)^{b} ; \\
\theta_{r, d 50}=0.021+0.015 e^{-20 F} ; \\
b=\frac{0.67}{1+\exp \left(1.5-\frac{d_{i}}{d_{50}}\right)}
\end{gathered}
$$


where $\mathrm{F}$ is the proportion of sediment in surface-size distribution. To calculate the local bed shear stress, this study adopts the approach based on the quadratic stress law.

$$
\tau_{\boldsymbol{b}}=\rho C_{d}|\mathbf{V}| \mathbf{V}
$$

where $C_{d}=g / C^{2}$, is a drag coefficient; the Chezy number (C) was determined using the Chezy and Nikuradse's function as,

$$
C=18 \log \left(\frac{12 h}{k_{s}}\right)
$$

where $k_{s}$ is the Nikuradse's roughness height.

The morphological evolution is performed per grid cell at each time step to update the new bed elevation based on the results from equations (1) and (4). The governing equation is expressed as:

$$
\frac{\partial z_{b}}{\partial t}=\frac{1}{1-p} \sum_{i=1}^{N}\left[\frac{\left(q_{b i}-F_{i} q_{b * i}\right)}{L_{i}}\right]
$$

where $N$ is the number of sediment fractions.

\subsection{Formulation of Secondary Flow}

The depth-averaged turbulent stresses are determined by the Boussinesq approximation which has been widely used in the past [e.g., Abad et al., 2008; Begnudelli et al., 2010; Wu, 2004]. Many studies have reported that the effects of a secondary flow can be well formulated through including dispersion terms in the governing equations of the 2-D flow model [Begnudelli et al., 2010; Duan and Nanda, 2006; Lane, 1998; Song et al., 2012]. The dispersion terms are generally delivered from the difference of the depth-averaged velocity and the vertical varying velocity. They are expressed as:

$$
\begin{gathered}
D_{x x}=\frac{1}{h} \int_{z_{0}}^{z_{0}+h}[u(z)-u]^{2} d z \\
D_{x y}=D_{y x}=\frac{1}{h} \int_{z_{0}}^{z_{0}+h}[u(z)-u][v(z)-v] d z \\
D_{y y}=\frac{1}{h} \int_{z_{0}}^{z_{0}+h}[v(z)-v]^{2} d z
\end{gathered}
$$

where $z_{0}$ is the zero velocity level; $u(z), v(z)$ represents the $\mathrm{x}$ and $\mathrm{y}$ components of the vertically varying velocity, respectively, $u, v$ are the depth-averaged flow velocity in $x$ and $y$ direction, respectively. To calculate the vertical varying velocity both in the streamwise and transverse directions, a number of approaches have been proposed [e.g., De Vriend, 1977; Guymer, 1998; Odgaard, 1986; Wu et al., 2005]. This study employed Odgaard's equation because of its robustness and simplicity. De Vriend's equation was also used to verify the difference caused by the choice of the different formulations for the vertical streamwise and transverse velocity. Odgaard's equation was proposed based on the linear transverse velocity profiles over the depth. The longitudinal and transverse velocities are given as [Odgaard, 1986]:

$$
\begin{gathered}
u_{I}(z)=U \frac{m+1}{m} \xi^{1 / m} \\
u_{t}(z)=2 v_{s}\left(\xi-\frac{1}{2}\right), \quad v_{s}=U \frac{2 m+1}{2 \kappa^{2} m} \frac{h}{r_{c}}
\end{gathered}
$$

where $u_{l}(z), u_{t}(z)$ are the longitudinal and transverse velocity components in the streamline coordinates, respectively; $U$ is the depth-averaged longitudinal velocity; $m=\kappa C / g^{0.5}$ and $\kappa=0.41$ is von Karman's constant; $v_{s}$ represents the transverse velocity at the free surface; $\xi=\left(z-z_{0}\right) / h$ is dimensionless distance from the bed; $r_{c}$ is the radius of channel curvature which can be measured from the outside of the bankfull channel to the intersection point of two lines that perpendicularly bisect the tangent lines of each curve departure point. In real-world cases, it can be measured based on the GIS base map. For a channel with multiple 
bends, similar measured method can be adopted. Following the study [Begnudelli et al., 2010], integration of equations (10) using the velocity profiles equation (11) yields:

$$
D_{l l}=\frac{U^{2}}{m(2+m)} ; \quad D_{l t}=D_{t l}=\frac{U v_{s}}{1+2 m} ; \quad D_{t t}=\frac{v_{s}^{2}}{3}
$$

For de Vriend's equation, the velocity distribution over the depth was derived by adopting a perturbation method. The depth-averaged method was used to simplify the 3-D curved channel problems into 2-D problems, which gave reasonable predictions of velocity and depth. Afterward, the model has been widely applied [Lien et al., 1999; Song et al., 2012]. Following [Lien et al., 1999], the dispersion terms are written in the streamline coordinates as:

$$
D_{\| l}=\frac{U^{2}}{m^{2}} ; \quad D_{l t}=D_{t l}=\frac{U V}{m^{2}}+\frac{h U^{2}}{r_{c} \kappa^{2}} F F 1 ; \quad D_{t t}=\frac{V^{2}}{m^{2}}+\frac{2 h U V}{r_{c} \kappa^{2}} F F 1+\frac{h^{2} U^{2}}{r_{c}^{2} \kappa^{4}} F F 2
$$

where $V$ are the depth-averaged transverse velocity in the streamline coordinates, respectively;

$$
\begin{gathered}
F F 1=\int_{0}^{1}(1+\ln \xi) f_{s}(\xi) d \xi ; F F 2=\int_{0}^{1} f_{s}^{2}(\xi) d \xi \\
f_{m}(\xi)=1+\frac{1}{m}(1+\ln \xi) ; f_{s}(\xi)=2 F_{1}(\xi)+\frac{1}{m} F_{2}(\xi)-2\left(1-\frac{1}{m}\right) f_{m}(\xi) \\
F_{1}(\xi)=\int_{0}^{1} \frac{\ln \xi}{\xi-1} d \xi ; \quad F_{2}(\xi)=\int_{0}^{1} \frac{\ln ^{2} \xi}{\xi-1} d \xi
\end{gathered}
$$

Defining the angle of the depth-averaged velocity vector measured counterclockwise from the $x$ direction as $\varphi$, the dispersion terms (equations (12) and (13)) in the curvilinear coordinates can then be converted to the Cartesian coordinate system by:

$$
\left[\begin{array}{ll}
D_{x x} & D_{x y} \\
D_{y x} & D_{y y}
\end{array}\right]=\mathbf{M}(\varphi)\left[\begin{array}{cc}
D_{l l} & D_{l t} \\
D_{t l} & D_{t t}
\end{array}\right] \mathbf{M}^{\boldsymbol{T}}(\varphi)
$$

where $\mathbf{M}(\varphi)=\left[\begin{array}{cc}\cos \varphi & -\sin \varphi \\ \sin \varphi & \cos \varphi\end{array}\right]$, such that

$$
\begin{gathered}
D_{x x}=D_{\| /} \cos ^{2} \varphi-2 D_{l t} \sin \varphi \cos \varphi+D_{t t} \sin ^{2} \varphi \\
D_{x y}=\left(D_{\|}-D_{t t}\right) \sin \varphi \cos \varphi+D_{l t}\left(\cos ^{2} \varphi-\sin ^{2} \varphi\right) \\
D_{y y}=D_{\| l} \sin ^{2} \varphi+2 D_{l t} \sin \varphi \cos \varphi+D_{t t} \cos ^{2} \varphi
\end{gathered}
$$

equations (14a)-(14c) are formulated for the effect of secondary flow which is included in the governing equations of the flow model.

\subsection{Numerical Solution}

The model (equations (1), (4), and (9)) is solved numerically by a well-balanced Godunov-type finite volume method (FVM) based on Cartesian coordinates and details can be found by referring to the previous publications [Guan et al., 2013, 2014]. The homogenous flux approach was used to address the bed slope source term treatment and wetting/drying. To update the variables in each cell, the following equation is used.

$$
\mathbf{U}_{i, j}^{n+1}=\mathbf{U}_{i, j}^{n}-\frac{\Delta t}{\Delta x}\left(\mathbf{E}_{i, j}^{*}-\tilde{\mathbf{E}}_{i, j}^{*}\right)-\frac{\Delta t}{\Delta y}\left(\mathbf{F}_{i, j}^{*}-\tilde{\mathbf{F}}_{i, j}^{*}\right)+\Delta t \mathbf{S}_{i, j}
$$

where the vector $\boldsymbol{E}_{i, j}^{*}=\boldsymbol{E}_{i+1 / 2, j}^{*}-\boldsymbol{E}_{i-1 / 2, j}^{*} \boldsymbol{F}_{i, j}^{*}=\boldsymbol{F}_{i, j+1 / 2}^{*}-\boldsymbol{F}_{i, j-1 / 2}^{*}$ are the difference of the fluxes at the left and right interfaces of the cell $(i, j)$ in the $x$ and $y$ direction; $\tilde{\boldsymbol{E}}_{i, j}^{*}$ and $\tilde{\boldsymbol{F}}_{i, j}^{*}$ represents the flux difference of turbulent and dispersion stresses at the left and right interfaces of the cell $(i, j)$ in the $x$ and $y$ direction; $\Delta t, \Delta x, \Delta y$ are the time step, cell size in the $x$ and $y$ direction, respectively. To calculate the intercell numerical fluxes of the flow model, a weighted average flux (WAF) of total variation diminishing (TVD) method is employed with a flux limiter function. The TVD-WAF scheme is second-order accurate in space and time by solving the 
conventional Riemann problem associated with the first-order Godunov scheme. A detailed description can be found in Guan et al. [2013]. Similar to updating the hydrodynamic variables, the sediment concentration is updated at the same cell and time step based on the sediment intercell flux $\mathbf{C}^{*}$ as follows,

$$
c_{i, j}^{t+\Delta t}=c_{i, j}^{t}-\alpha\left[\frac{\Delta t}{\Delta x}\left(c_{i+\frac{1}{2}, j}^{*}-c_{i-\frac{1}{2}, j}^{*}\right)+\frac{\Delta t}{\Delta y}\left(c_{i, j+\frac{1}{2}}^{*}-c_{i, j-\frac{1}{2}}^{*}\right)\right]+\Delta t S_{c(i, j)}
$$

where $t$ represents the time; $S_{c}$ is the source term shown in the right hand side of equation (4). The sediment flux $C^{*}$ is calculated using the following equation,

$$
\mathbf{C}^{*}=c^{*}(\vec{i}+\vec{j})=\left\{\begin{array}{l}
\left(\left.\mathbf{E}_{l r}^{*}\right|_{1} \vec{i}+\left.\mathbf{F}_{l r}^{*}\right|_{1} \vec{j}\right) c_{l} S_{*} \geq 0 \\
\left(\left.\mathbf{E}_{l r}^{*}\right|_{1} \vec{i}+\left.\mathbf{F}_{l r}^{*}\right|_{1} \vec{j}\right) c_{r} S_{*}<0
\end{array}\right.
$$

where $c_{l}$ and $c_{r}$ are the volumetric sediment concentration at the left and right cells; $\left.\boldsymbol{E}_{\mid r}^{*}\right|_{1},\left.\boldsymbol{F}_{\mid r}^{*}\right|_{1}$ represent the first component of the flow intercell flux calculated by the TVD-WAF scheme in the $x$ and $y$ directions, respectively; $S_{*}$ denotes the middle wave speed calculated by using equation recommended by Toro [2001]. A variable time step $\Delta \mathrm{t}$, adapted to local flow conditions, is calculated at each time step based on a fixed courant number ( $C F L=0.6$ here) for stability.

\section{Study Site}

The study domain is a short reach of River Greta which is located in Keswick (UK) (Figure 1a). The river reach is approximately $160 \mathrm{~m}$ long and the channel width varies from 10 to $40 \mathrm{~m}$. Field evidence showed that morphological changes occurred at the sharp bend during flood periods. Thus, the in-channel deposited sediments have to be dredged regularly. Field surveys at 16 cross sections (Figure 1a) were conducted before and after a flooding year by the Environment Agency. The scarce field data set was exploited to validate the capability of the developed 2-D model in modeling bar formation at the natural bend. Digital Terrain Models (DTMs) with $1 \mathrm{~m} \times 1 \mathrm{~m}$ resolution were constructed based on the measured raw point data from August 2005 and July 2006 to represent the bed terrain before and after the flooding period 20052006. The hydrograph data with a 15 min interval were measured in the Low Briery station, upstream of the study site from January 2005 to July 2006 (Figure 1c). It is shown that most of the time the flow discharge is

(a)
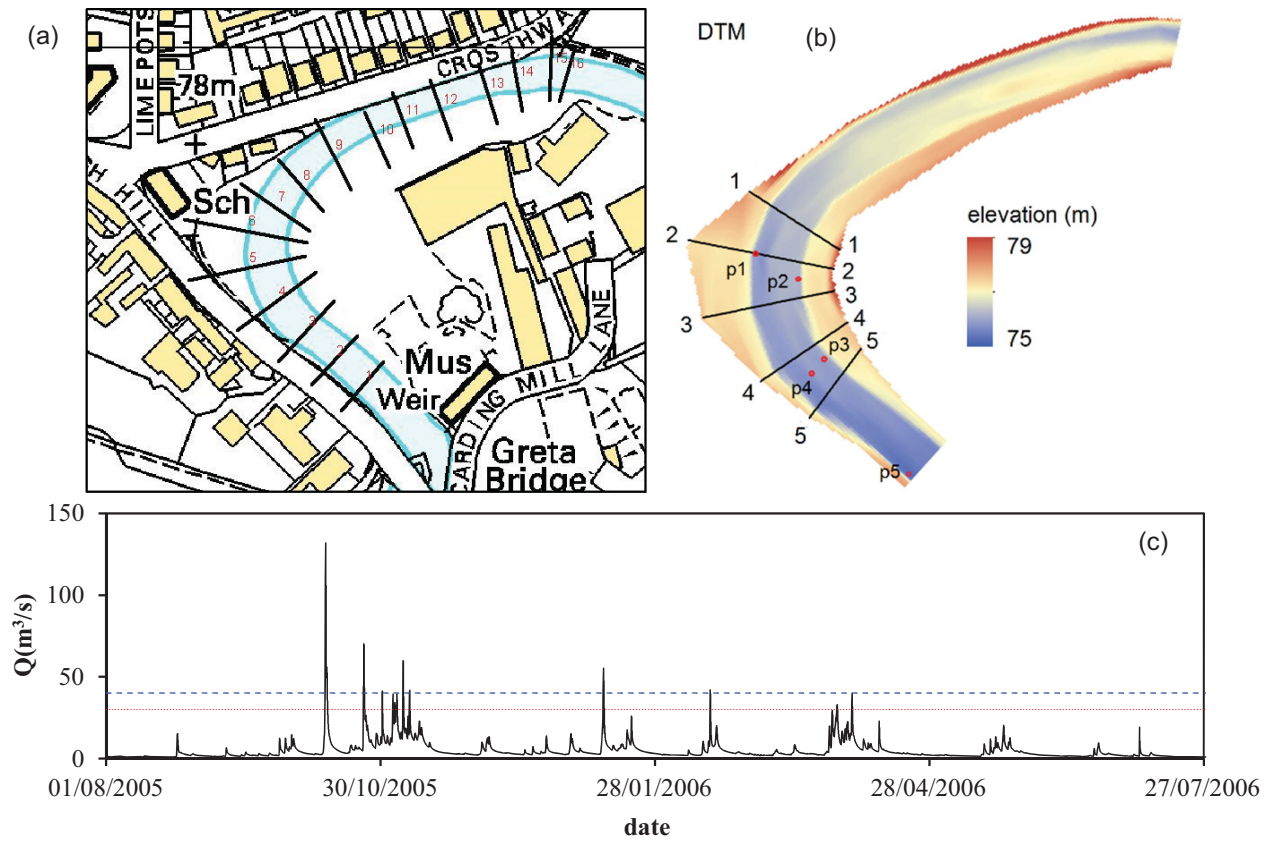

(c)

Figure 1. (a) The study reach with the 16 cross sections, (b) the constructed DTM before flooding ( $1 \mathrm{~m} \times 1 \mathrm{~m})$, and (c) the inflow hydrograph recorded at the Low Briery gauge station. 


\begin{tabular}{|c|c|c|c|c|c|c|c|c|c|}
\hline \multirow[b]{2}{*}{ Run } & \multirow[b]{2}{*}{ Nikuradse $k_{s}$} & \multirow{2}{*}{$\begin{array}{l}\text { Curvature } \\
\text { Radius (m) }\end{array}$} & \multicolumn{2}{|c|}{ Secondary Flows } & \multicolumn{3}{|c|}{ Bedload Formula } & \multirow[b]{2}{*}{ Inflow } & \multirow[b]{2}{*}{ Grain Size } \\
\hline & & & Odgaard & deVriend & MPM & Cheng & WC2003 & & \\
\hline R1 & 0.03 & $\times$ & $x$ & $\times$ & $\checkmark$ & $\times$ & $x$ & $\mathrm{H} 1$ & Multiple \\
\hline R2 & 0.03 & 80 & $\sqrt{ }$ & $\times$ & $\checkmark$ & $x$ & $x$ & $\mathrm{H} 1$ & Multiple \\
\hline R3 & 0.03 & 60 & $\sqrt{ }$ & $\times$ & $\checkmark$ & $\times$ & $x$ & $\mathrm{H} 1$ & Multiple \\
\hline R4 & 0.03 & 60 & $\sqrt{ }$ & $x$ & $x$ & $\sqrt{ }$ & $x$ & $\mathrm{H} 1$ & Multiple \\
\hline R5 & 0.04 & 60 & $\sqrt{ }$ & $x$ & $\checkmark$ & $x$ & $x$ & $\mathrm{H} 1$ & Multiple \\
\hline R6 & 0.05 & 60 & $\sqrt{ }$ & $\times$ & $\checkmark$ & $\times$ & $\times$ & $\mathrm{H} 1$ & Multiple \\
\hline R7 & 0.04 & 60 & $\sqrt{ }$ & $\times$ & ป & $x$ & $x$ & $\mathrm{H} 2$ & Multiple \\
\hline R8 & 0.05 & 60 & $\sqrt{ }$ & $x$ & $\checkmark$ & $x$ & $x$ & $\mathrm{H} 1$ & Single \\
\hline R9 & 0.03 & 60 & $x$ & $\sqrt{ }$ & $\times$ & $x$ & $x$ & $\mathrm{H} 1$ & Multiple \\
\hline $\mathrm{R} 10$ & 0.03 & 60 & $\sqrt{ }$ & $x$ & $\sqrt{ }$ & $\times$ & $\sqrt{ }$ & $\mathrm{H} 1$ & Multiple \\
\hline
\end{tabular}

smaller than $30 \mathrm{~m}^{3} / \mathrm{s}$. Field evidence demonstrates that the geomorphological changes induced by low flows are insignificant. Thus this study only focuses on the flood events greater than a threshold to save computational time. Both 30 and $40 \mathrm{~m}^{3} / \mathrm{s}$ were used as the threshold to test model sensitivity to this value.

According to the field observation, the riverbed is composed of a wide range of sediment particles including gravel and boulder. It was estimated as being composed of multiple groups of sediments with the diameters of $0.02 \mathrm{~m}(30 \%), 0.04 \mathrm{~m}(40 \%)$, and $0.06 \mathrm{~m}$ (30\%). To explore the importance of grain-size parameterization, a single constant value $0.03 \mathrm{~m}$ was also used in R8 (Table 1). As the estimation of curvature radius in reality may have some errors, two scenarios with the radius of 60 and $80 \mathrm{~m}$ were modeled in order to explore its sensitivity. Table 1 shows the setup of each runs. Therein, $\mathrm{H} 1$ denotes the flows greater than $40 \mathrm{~m}^{3} / \mathrm{s} ; \mathrm{H} 2$ denotes the flows greater than $30 \mathrm{~m}^{3} / \mathrm{s}$. The model sensitivity to the inflow discharges was evaluated and the result implies that the recorded flows lower than $40 \mathrm{~m}^{3} / \mathrm{s}$ only have an insignificant contribution to bed aggradation and degradation. Thus, the inflow over $40 \mathrm{~m}^{3} / \mathrm{s}$ is sufficient for the application case.

\section{Results}

\subsection{Model Validation in Flume Cases}

In this section, two flume cases are tested to verify the capability of the model in simulating flow dynamics [De Vriend and Koch, 1978] and bed changes [Odgaard and Bergs, 1988].

\subsubsection{De Vriend and Koch [1978]}

This experiment was conducted by De Vriend and Koch [1978] to investigate the steady flow of water in a curved flume where the bed configuration was set as expected in a natural river bend. The flume consists of a $38 \mathrm{~m}$ straight section followed by a $90^{\circ}$ bend with a radius of curvature of $50 \mathrm{~m}$ (Figure 2a). In the straight reach (entrance to $\mathrm{B} 0$ ), the channel was prismatic, with a parabolic cross section and a zero longitudinal slope. From BO to $\mathrm{C}$, the bed is changed from a parabolic cross section to a cross section with a point bar near the inner wall and a deeper channel near the outer wall. Then cross sections from C1 to E0 are the same as $\mathrm{CO}$, with a longitudinal slope of 0.0003 . The flume width was $6 \mathrm{~m}$. More details about the experiment can be found in De Vriend and Koch [1978].

For simulation, the flume is discretized by rectangular meshes with a size $0.2 \mathrm{~m} \times 0.2 \mathrm{~m}$. A fixed Courant number of 0.6 is used. Following the experiment, the bed is fixed uneven bed, and the Nikuradse roughness height $k$ is equal to $0.001 \mathrm{~m}$. The scenario with an input discharge of $0.463 \mathrm{~m}^{3} / \mathrm{s}$ was modeled. The flow depth at the upstream boundary of the channel was kept constant $0.26 \mathrm{~m}$ (yielding average velocity of about $0.4 \mathrm{~m} / \mathrm{s}$ ). Clearly, Figures $2 b-2 d$ indicates that the velocity near the outer bank increase and it decreases near the inner bank due to the secondary flow correction. At B1, the Root Mean Squared Error (RMSE) for the two scenarios shows slightly difference, but RMSE with the secondary flow correction clearly becomes smaller at C1 and D1 which is located at the middle of the bend. This means that the model with an inclusion of secondary flow terms improves the predication of velocity profiles at the bend. Overall, the simulated velocities are in good agreement with the measured results. This case verifies the capability the model in simulating velocities at a bend.

\subsubsection{Odgaard and Bergs [1988]}

The experiment was performed in an $180^{\circ}$ curved flume in the lowa Institute of Hydraulic Research by [Odgaard and Bergs, 1988], and the bed geometry and sediment material was described below: two $20 \mathrm{~m}$ long 

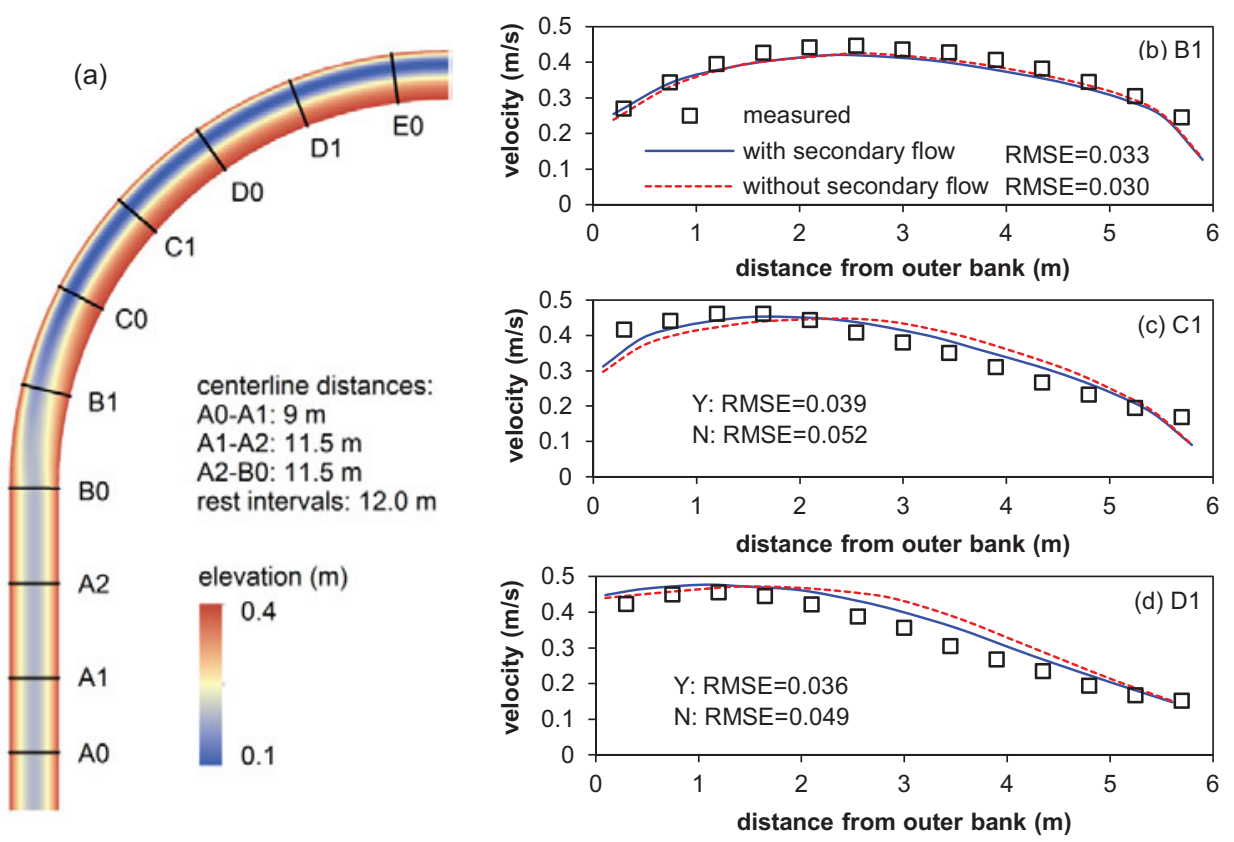

Figure 2. (a) Flume bed geometry and the location of cross sections; and the comparison of measured and simulated velocity profiles with and without secondary flow effects at $0.4 \mathrm{~h}$ in the (b) B1, (c) C1, and (d) D1.

straight reaches were connected by a 180 bend with $13.11 \mathrm{~m}$ radius, and the cross section was trapezoidal and vertical side walls with $2.44 \mathrm{~m}$ wide; the channel was initially covered by sand with a $0.23 \mathrm{~m}$ thick layer and median diameter of $0.3 \mathrm{~mm}$. Flow conditions include: the discharge was $0.153 \mathrm{~m}^{3} / \mathrm{s}$ at upstream inlet, water level at the outlet is $0.38 \mathrm{~m}$ above the channel bottom, and the centreline average flow depth and velocity are $0.15 \mathrm{~m}$ and $0.45 \mathrm{~m} / \mathrm{s}$, respectively. More details about the experiment can be found in Odgaard and Bergs [1988].

For simulation, the flume is discretized by uniform meshes with a size of $0.04 \mathrm{~m} \times 0.04 \mathrm{~m}$. Fixed courant number of 0.6 is used. The Darcy frictional factor $f=0.067$ is used following Odgaard and Bergs [1988]. The model is run until flow and sediment reaches a steady state. Following Bohorquez and Ancey [2016], we evaluated the model's performance using the Root Mean Squared Error (RMSE) and the Brier Skill Score (BSS) as:

$$
B S S=1-\frac{\sum_{1}^{N}\left(z_{i}^{\text {mes }}-z_{i}^{\text {num }}\right)^{2}}{\sum_{1}^{N}\left(z_{i}^{\text {mes }}-z_{i, t=0}^{\text {mes }}\right)^{2}}
$$

where superscripts num and mes refer to numerical and measured bed elevation, respectively, and $N$ is the total number of point data. Equation (18) compares errors in the model outputs with a reference "prediction," assumed to be the initial bed level [El kadi Abderrezzak and Paquier, 2009]. Figure 3 demonstrates the measured and simulated bed profiles with RMSE and BSS at four cross sections. It is clear that the model with secondary flow effects predicts the changes in the bend reasonably well. At the cross section of $\theta=45^{\circ}$, BSS reaches 0.963 , which demonstrates an excellent fit. BSS at the other three cross sections is in a range of $0.4-0.6$, which means a fairly good agreement between modeled and measured results. Overall, the bed profiles are well predicted with a common feature, which is that the bed at outer bank is eroded and deposition occurs at the inner bank. This test case indicates that our model can predict bed deformation in a flume bend reasonably well.

\subsection{Application to a Natural Bend of River Greta}

4.2.1. Effect of a Secondary Flow on Hydrodynamics

Figure 4 a demonstrates a reasonable predication of the model in modeling water stage at the outlet. The velocity profiles in Figures $4 \mathrm{~b}-4 \mathrm{e}$ have clearly shown that the secondary flow correction lead to the velocity 

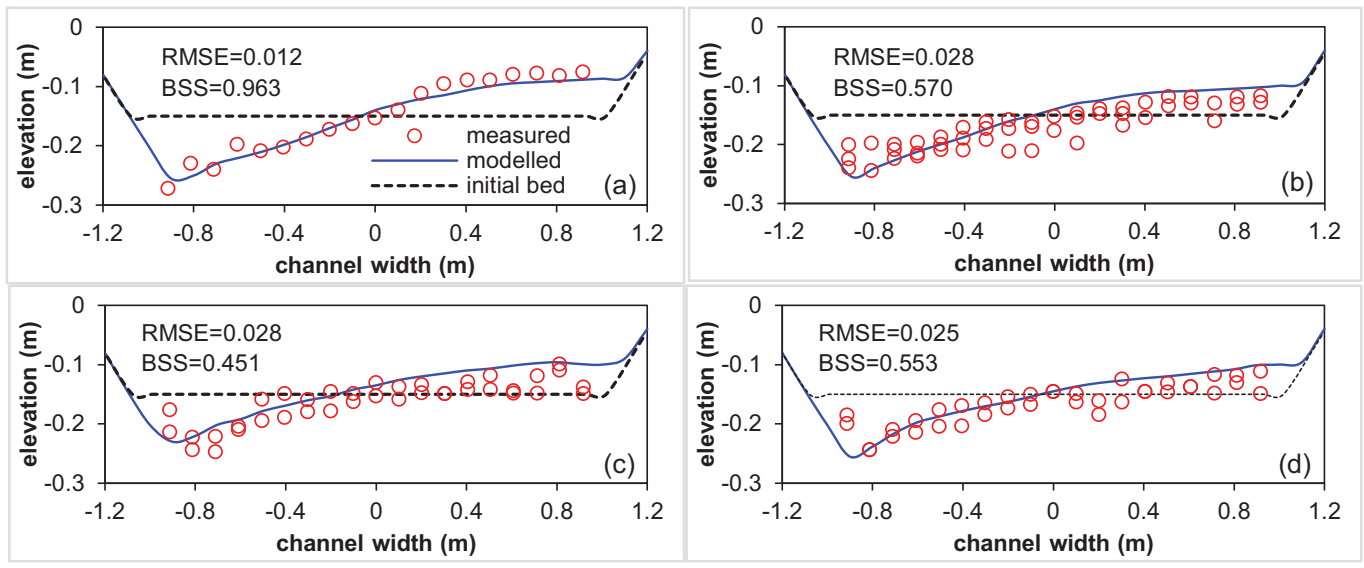

Figure 3. Comparisons of measured and simulated bed changes as cross sections (a) $\theta=45^{\circ}$, (b) $\theta=90^{\circ}$, (c) $\theta=135^{\circ}$, and (d) $\theta=180^{\circ}$.
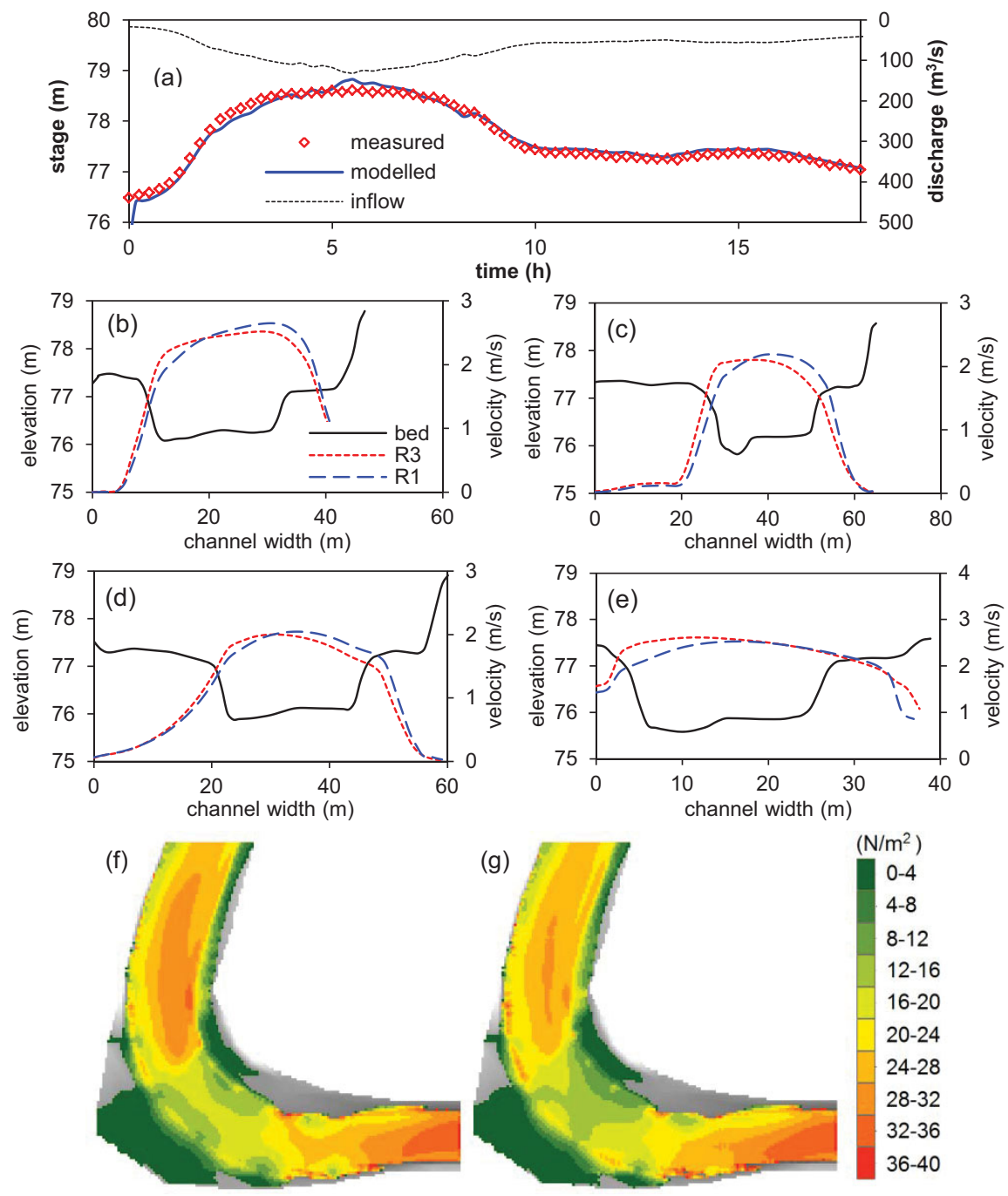

Figure 4. (a) Modeled (R1) and measured water stages at the $\mathrm{p} 5$; (b-e) simulated velocity profiles at $\mathrm{Q}=70 \mathrm{~m}^{3} / \mathrm{s}$ without (R1) and with (R3) the secondary flow effect at four cross sections cs1-1, cs2-2, cs3-3, and $\operatorname{cs5} 5$, for each cross section, the outer bank is in the left hand side, and the inner bank is in the right hand side; (f) bed shear stress at $Q=70 \mathrm{~m}^{3} / \mathrm{s}$ without (R1) and with (R3) secondary flows. 
increase at the outer bank and decrease at the inner bank. The higher velocity occurs near the outer bank around the bend (e.g., at cs2-2, cs3-3, and cs4-4). Quantitatively, the change in the value of the peak velocity is rather insignificant. The peak velocity is only decreased by $1 \%-5 \%$ at the four cross sections. However, it is clear that the velocity is redistributed due to the presence of the secondary flow effect. This must lead to the redistribution of bed shear stress at the bend which is a fundamental driver of morphological change. Figure $4 \mathrm{f}$ indicates that the bed shear stress around the bend $\left(0-16 \mathrm{~N} / \mathrm{m}^{2}\right)$ is clearly smaller than that at both upstream and downstream locations where the high value is in a range of $24-36 \mathrm{~N} / \mathrm{m}^{2}$. It is shown that the bed shear stress with a secondary flow correction is slightly smaller around the bend and at the upstream of the bend; also, the bed shear stress at the outer bank increases from 8-12 to $12-16 \mathrm{~N} / \mathrm{m}^{2}$, and it decreases from $8-12$ to $4-8 \mathrm{~N} / \mathrm{m}^{2}$ at the inner bank.

\subsubsection{Effect of a Secondary Flow on Morphodynamics}

The effect of a secondary flow on hydrodynamics must lead to the modification of postflood bed deformation because all the sediment-related formulations are calculated based on the hydrodynamics, e.g., bed shear stress, sediment transport rate, and capacity. To verify the effect of a secondary flow correction on morphological changes, the results of R1, R2, R3, and R9 (Table 1) are demonstrated in Figure 5. It indicates that without the secondary flow effect (R1), the deposition mainly occurs in two regions: the outer bank toe and the inner bank at the downstream of the bend. The deposition in both regions appears to be equally significant. This contradicts with the common understanding on alluvial processes at a bend. For the specific event here, the velocity and the bed shear stress are reduced at the bend due to the widening of the channel. This seems be a reason that results in the deposition at the outer bank toe. However, with the secondary flow effect, R2, R3, and R9 predicts a bar formation with a larger size at the inner bank, and the deposition at the outer bank toe is notably alleviated. As shown in Figure 5, the difference between R1 and $R 2, R 3, R 9$ further verifies that a secondary flow correction reduces the deposition at the outer bank toe, e.g., the reduction is in a range of $0-0.45 \mathrm{~m}$ for $\mathrm{R} 3$, and increases bar formation at the inner bank $(0-0.45 \mathrm{~m}$ for R3). Further, the bar location is approaching the bend in contrast to that for R1 without the secondary flow correction. The difference of R2 and R3 indicates that for a smaller radius (R3: $r=60 \mathrm{~m}$ ) which means the bend is sharper, the deposition depth and area at the outer bank toe will further become smaller, and meanwhile an increase of deposition depth occurs at the inner bank (R3-R2). With the same curvature radius, R3 and R4 adopt two different equations to calculate the secondary flow correction. Overall, both approaches improve the bar formation at the bend in comparison to R1 without a secondary flow correction. However, Odgaard equation predicts a slightly larger bar, and a smaller amount of deposition at the outer bank toe than deVriend equation. It should be noted that the differences, R3-R2 and R9-R3, appear to be less significant than those between R1 and R2, R3, R9. This implies that in spite of some sensitivity, a secondary flow plays a significant role in morphological changes at the natural bend, which has also been emphasized by some studies [e.g., Wang et al., 2014].

\subsubsection{Morphological Sensitivity to Uncertainty Variables}

Sediment transport formulae generally have limitations for application in reality because of their empirical derivation. The formulae of MPM, Cheng and WC2003 were used here to test the model sensitivity to the choice of this parameter. The results and comparison in Figure 6 indicates that the three formulae predict a similar bar formation at the bend in terms of both deposition pattern and location. The bar predicted by MPM and Cheng shows minor differences in a range of $-0.15 \mathrm{~m}$ to $0.15 \mathrm{~m}$. Compared to the two formulae, WC2003 predicts a relative larger bar at the bend. However, the difference is quite insignificant in comparison to bed changes. This manifests that the effects of the formula choice do not affect the deposition pattern and volume significantly. Therefore, this parameter is considered to be a less important variable deciding the bed erosion and deposition.

Figure 7 indicates that R6 predicts the largest bar formation at the inner bank of the bend among R3, R5, and R6 which have a roughness height of $0.03,0.04$, and $0.05 \mathrm{~m}$, respectively. The differences between each other clearly demonstrate that the bar size expands with the increase of roughness height, whilst the deposition area at the outer bank toe decreases, and meanwhile the erosion area becomes more severe. According to equation (7), the bed shear stress is altered due to the changes in roughness height. This causes a change of the quantification of the aggradation and degradation within the channel. However, the roughness height alters the overall value of in-channel bed shear stress, which differs from the secondary flow effect which redistributes the bed shear stress at the bend without significant changes in value. This is a main cause that all runs (R3, R5, and R6) with the secondary flow effect perform more reasonably in comparison to R1. 

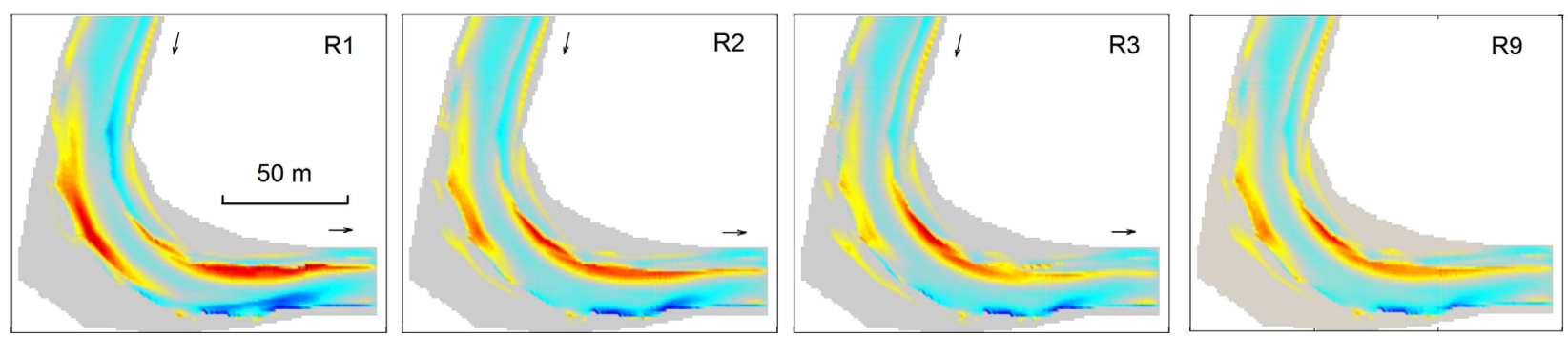

(m)
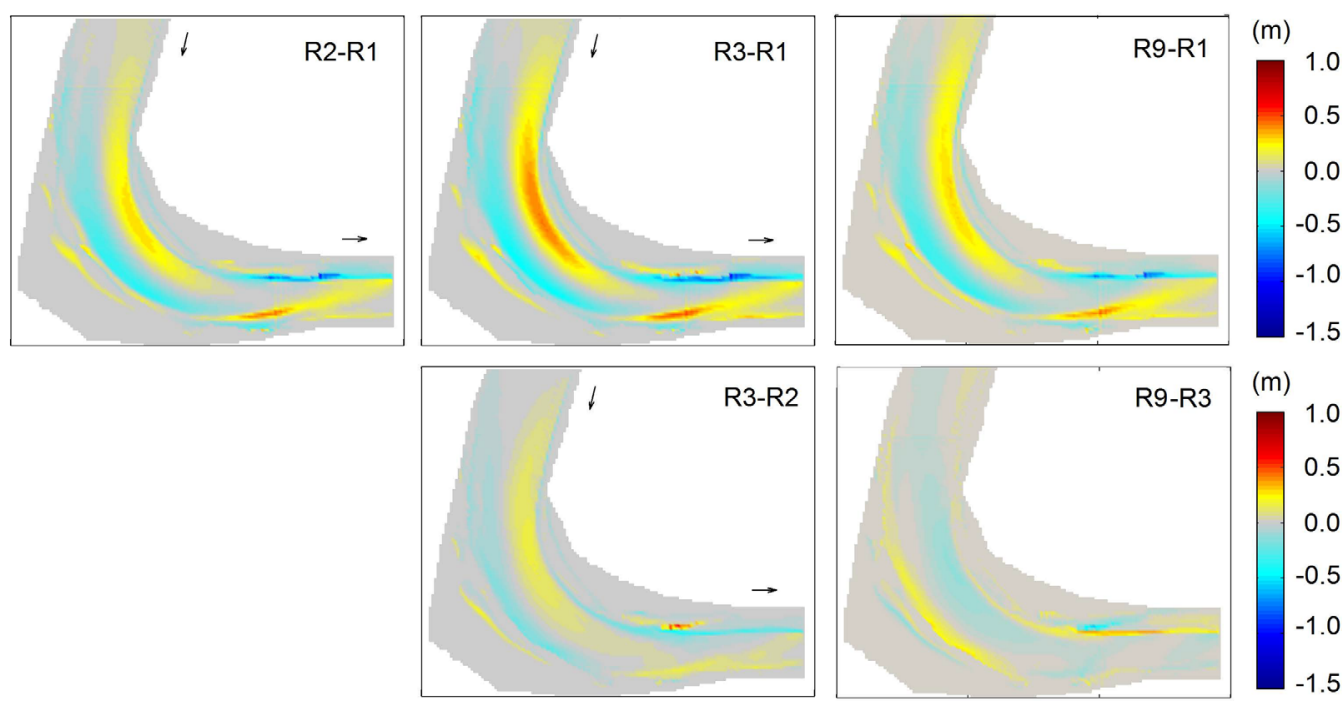


depth, positive value represents deposition.

To emphasize the importance of the parameterization of sediment particles, R8 with a constant median grain size was implemented and compared to R6 with multiple grain sizes. Figure 8 shows that the deposition predicted by R8 significantly differ from the simulation by R6. Specifically, the constant grain parameterization results in a much smaller bar formation at the inner bank of the bend, and meanwhile much
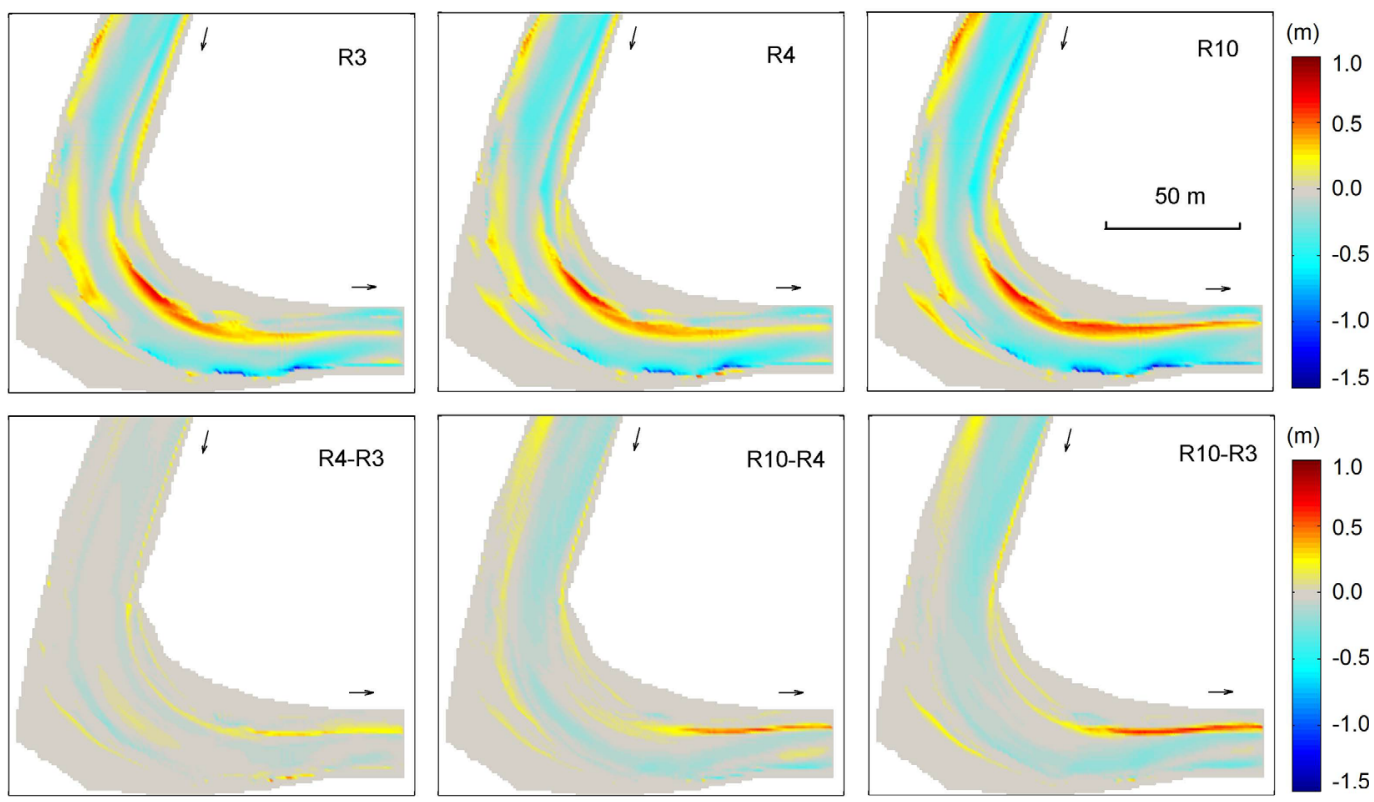

Figure 6. The simulated bed changes and the difference of R3, R4, and R10. 

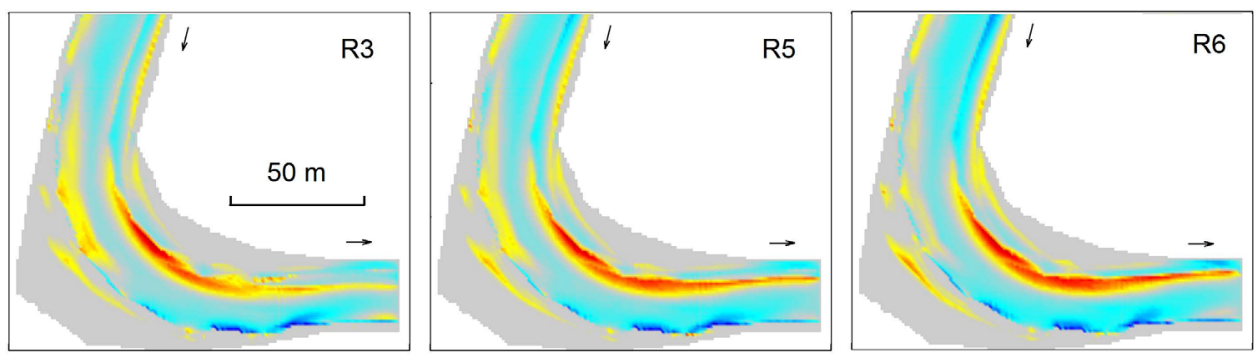

(m)


Figure 7. The simulated bed changes of R3, R5, and R6, and the difference of each other at the bend.

more deposition at the outer bank toe. Also at the channel exit R8 gains more erosion than R6. Both deposition areas have equivalent amount of degradation. This feature of bed changes at the bend is similar to that predicted by R1 without a secondary flow correction. This implies that grain-size parameterization is significant for the modeled morphological changes at the bend, not only in the bar size, but also the distribution pattern of bed changes. The results show that the simulated morphodynamics are sensitive to the grainsize parameterization. Accordingly, to parameterize the spatial grain-size in a practical way is highly important for good prediction of the morphodynamics at a bend. The grain-size parameterization is as important as the inclusion of the secondary flow effect.

From the viewpoint of temporal changes in bed elevation, Figure 9 indicates that the bed changes for R4, R5, R6, and R10 have same tendency at each point. Specifically, the bed elevation increase and decrease in a synchronous manner despite the fact that the change magnitude differs from each scenario. This implies that sediment transport formula and roughness height pose more significant impact on the quantification of bend changes, but less on the characteristics of aggradation and degradation. Without the secondary flow correction, R1 shows a clear different tendency in bed changes at the four points, particularly at the point 1 , point 2 , and point 3 , despite the fact that it predicts similar feature of bed change at initial time. Therefore, sediment transport pathway of R1 clearly differs from that of other runs with a secondary flow correction, resulting the postflood bed elevation being much different. Regarding R8 with a single constant grain size $\left(d_{50}=0.03 \mathrm{~m}\right)$, the temporal changes in bed elevation are also greatly different from R4-R6 and R10. For instance, the bed elevation at point 1 and point 2 does not change but remain constant after the first major flooding, i.e., sediment transport reaches an equilibrium state to the flow. It indicates that grainsize parameterization is critical for the morphodynamics at the bend apart from the secondary flow effect. Additionally, it should be noted that the simulated bed changes by all runs have a similar tendency at the
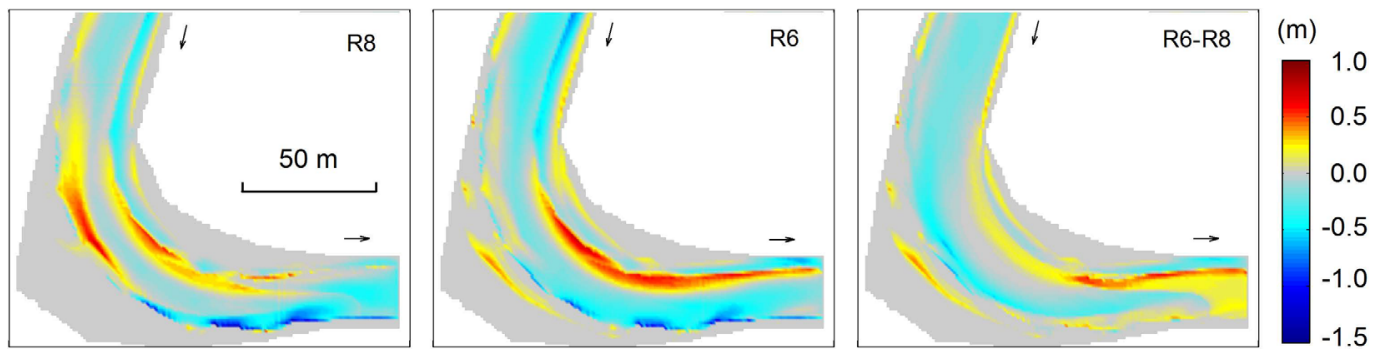

Figure 8. The simulated bed changes with multiple grain-sizes (R6) and single constant grain-size (R8), and the difference of the two runs. 

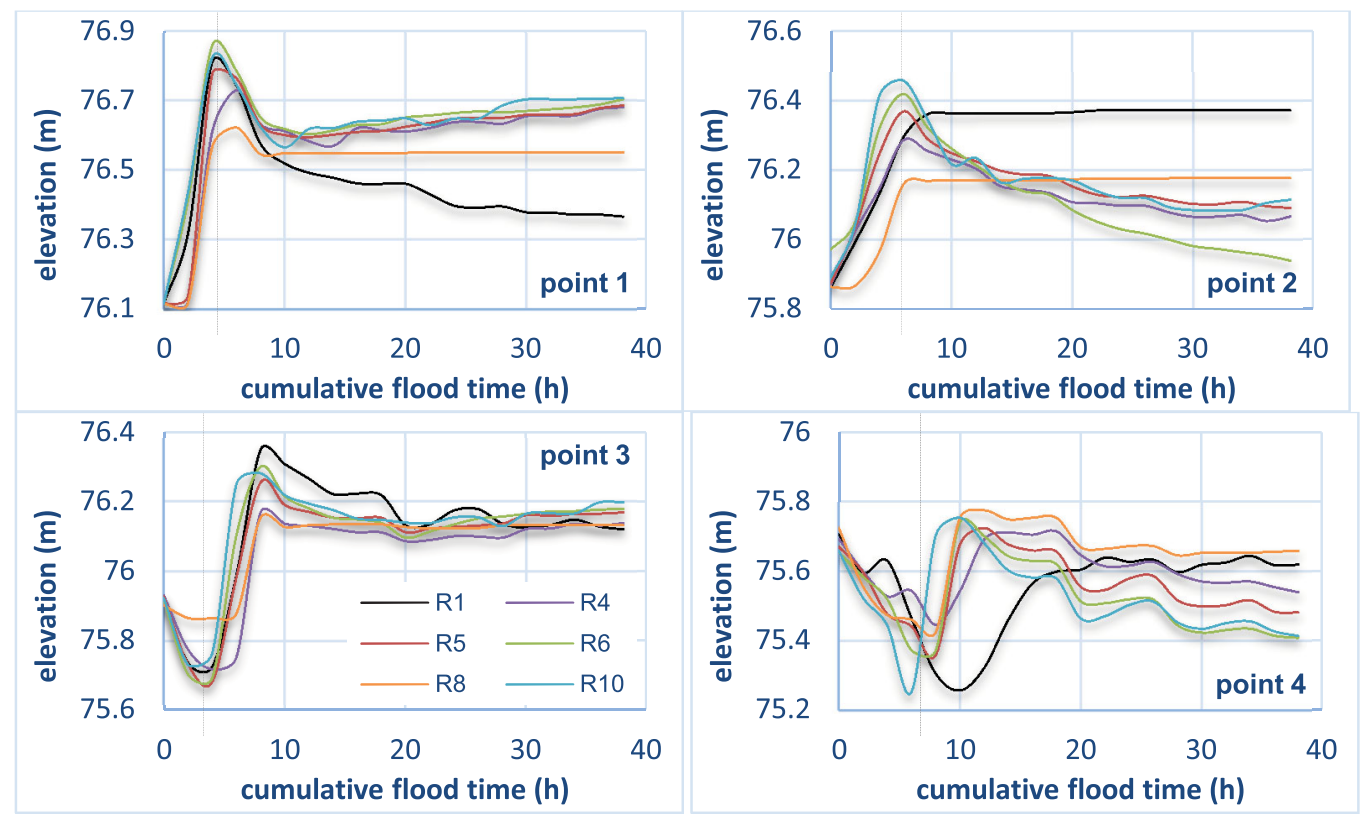

Figure 9. Temporal changes of bed elevation for R1, R4-6, and R8 at four points around the bend.

four points during the first stage of the flooding (before the vertical line in Figure 9). The differences after the line become increasingly significant.

4.2.4. Comparison to the Observations

Field measurements of the 16 cross sections after the flooding year from August 2005 to July 2006 were conducted. The DTM was constructed based on the field measurements in July 2006, and the deposition at the bend was generated by comparing the constructed DTMs before and after the flood period. Figure 10 demonstrates that the model with a secondary flow correction predicts the bar formation in general agreement with the measurement, including the location and pattern of the deposited bar which is located at the inner bank from cs1-1 to the exit of the channel. The simulated deposition depth is in a range of $0.0-$ $0.69 \mathrm{~m}$ which has a same magnitude to the observed deposition. A comparison at four cross sections also shows that the 2-D model predicts a similar profile shape with the measurement, i.e., deposition mainly occurs at the inner bank of the bend, whereas the simulated deposition is less than the observation. This confirms that the 2-D depth-averaged model has the capability of predicting the bar formation at the natural bend if including a secondary flow correction. However, the simulated bar size is smaller the observed one which is approximately 0.8 times larger. It is found that net erosion is observed in reality at the circular region of the inner bank which is different from the modeled bed. Also, at cs5-5 the model predicts severe erosion $(0.44 \mathrm{~m})$ at the outer bank toe of the bend, where no erosion is observed during field measurement. The differences are attributed to a number of reasons which will be discussed below.

\section{Discussion}

\subsection{Field Measurements}

It is always difficult to obtain field measurements of river geometry after the in real-world flood events. The original data set of channel geometry was provided by the Environment Agency, in a format of raw point data at 16 cross sections (Figure 1a). DTMs before and after the flooding period were constructed based on the raw point data in order to conduct 2-D modeling. To analyze the differences of DTMs (DoD) before and after the flooding, it is found that the total erosion volume is approximately $888 \mathrm{~m}^{3}$ during the flooding year, while the total deposition volume of sediment reaches about $955 \mathrm{~m}^{3}$, which is $67 \mathrm{~m}^{3}$ larger than the erosion volume. In general, the deposited sediment comes from the local eroded sediment provided that there are no extra sediment sources. Therefore, it is likely that there is upstream sediment flux entering the studied reach. However, it is difficult to estimate this sediment flux. Moreover, Figure 10 demonstrates a wide extent of bed erosion in the circular area, but nearly no erosion in the main channel near the outer bank. The distribution of bed shear 

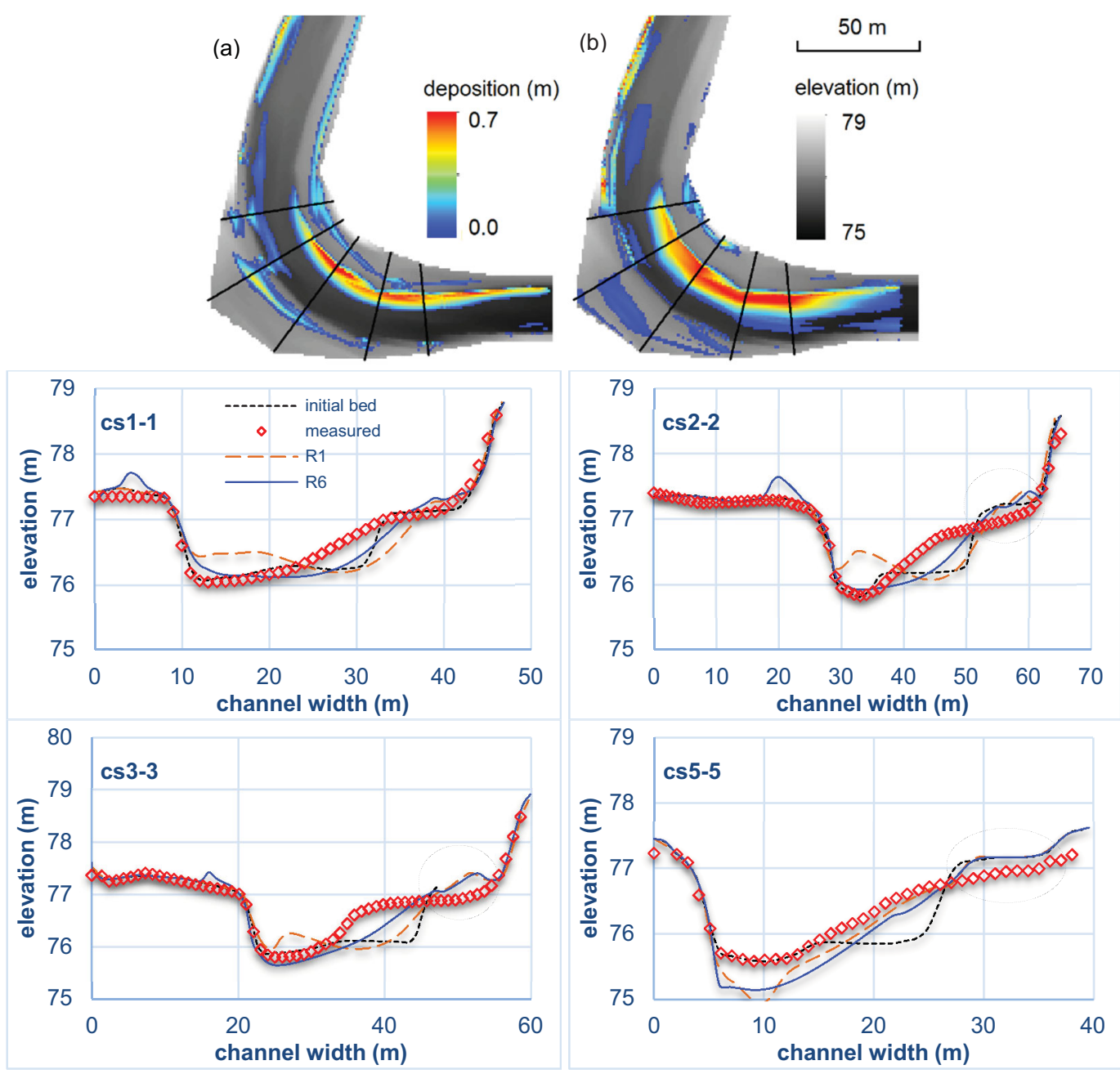

Figure 10. (a) Simulated deposition (R6) and (b) measured deposition, and bed profiles at four cross sections cs1-1, cs2-2, cs3-3, and $\operatorname{cs} 5-5$, note: R1 and R6 represents the results without and with secondary flow correction.

stress shows that this area has a lower bed shear stress than surrounding area, and the main channel has a higher bed shear stress than the two sides of the channel. The observed erosion in this area seems not to be caused by the flooding, but very likely by a sudden avalanching naturally or human interventions because the time interval of the measurement is nearly one year. Therefore, we consider that the 2-D model can predict the bar formation reasonably well because: (1) the time scale between the measurement and the simulation is different, the time interval between the two DEMs before and after the flood is 1 year, yet the simulation time is only $60 \mathrm{~h}$ flooding, so there must be extra interventions on the bed; (2) sediment flux from upstream is unable to be well quantified; and (3) accurate parameterization of sediment transport cannot be performed yet, such as sediment composition, viscosity, as well as sediment transport capacity.

\subsection{Physical Complexity to Model Morphological Changes at a Bend}

This paper developed a depth-averaged 2-D hydromorphodynamic model with a secondary flow correction which is validated in two small-scale experiments. The model was applied to model bar formation at a natural bend based on annual field survey data. Not only the secondary flow effect, but also a number of parameters were evaluated in order to explore the importance of each on morphodynamics in the curved channel.

For hydrodynamics, similar to the findings by the existing studies [Lien et al., 1999; Song et al., 2012], a secondary flow correction increases the velocity at the outer bank, but decreases it at the inner bank, leading to a higher velocity near the outer bank of the bend. The redistribution of the velocity field further causes a change of bed shear stress in distribution which drives the bed change pattern to be changed. The above 
comparison among R1, R2, R3, and R9 indicates that a secondary flow correction plays a vital role in terms of both distribution and quantification of bed aggradation and degradation at the bend. For the scenario without secondary flow effects, it is unlikely to predict a reasonable bar formulation. The deposition at the outer bank toe appears to be equally significant to the deposition at the inner bank area. The inclusion of a secondary flow correction dramatically improves the prediction of bar formation which is in general agreement to field survey date despite the fact that the bar size and the deposition at the outer bank toe are affected by a number of parameters. It has been reported that sediment-related parameters are crucial factors affecting sediment transport and thereby morphological changes. This raises a question that how important these parameters are in comparison to the secondary flow effect.

Although sediment transport formulae are regarded as having poor accuracy, the above results manifest that empirical-based sediment transport formulae do not result in huge difference to the modeled bed changes. MPM, Cheng and WC2003 predict highly similar bar pattern, but slightly different bar size. This does not imply that the three functions are accurate because the empirical formulae always have limitations in application. This indicates that sediment transport functions likely affect the quantification of bed changes, but the feature of erosion and deposition is hardly influenced. Therefore, the importance of this variable is much less than the secondary flow effects. The impact of roughness height is to increase or decrease the flow velocity and water depth with an equal magnitude in the whole area, resulting in an overall change in bed shear stress, but not influencing the distribution feature at the bend. Thus, R3, R5, and R6 with different roughness height predict morphological changes with a similar feature but different bar size. Similar to sediment transport formula, roughness height cannot affect the feature of bed changes, but determine how much sediment is eroded and deposited. However, it is found that the parameterization of grain-size has significant effects on the volume and location of bed changes at the bend. Provided that the representative size of sediment materials within channel is properly parameterized, it is likely that the model even with secondary flow effects cannot reasonably predict morphodynamics at a natural bend (e.g., the simulated bed changes by R9). The fundamental reason is that grain-size parameterization has direct impact on a number of factors, such as settling velocity of a particle, threshold of incipient motion, dimensionless bed shear stress, and sediment transport capacity. The change in each factor can lead to a modification of bed erosion and deposition. For a bed constituted by a wide range of grain-sizes, a single constant grain-size apparently misrepresents the real situation, which will lead to two bars at the bend (R8). The bar at the outer bank was significantly overpredicted in comparison to the observed deposition (Figure 10b). Thus, it is crucial to parameterize grain sizes spatially varying to model morphological changes at a natural curved channel. This factor is equally important with a secondary flow correction. Moreover, this study found that bed changes have a similar feature in spite of the difference in depth at the rising climb of the first flood which has the highest peak $\left(128 \mathrm{~m}^{3} / \mathrm{s}\right.$ ) (Figure 9). This denotes that a rapid flood can induce a rapid bed response, where the main flow is more dominant than the secondary flow effect. Thus during this period, the secondary flow seems not to have significant impact on bed changes. In the sequent flood with smaller discharge, secondary flow effects appear to be increasingly important on modifying the distribution of bed erosion and deposition.

Whether a 2-D model can simulate hydrodynamics and morphodynamics in a curved channel has been controversial. Some studies [Alho and Mäkinen, 2010; Kasvi et al., 2015; Lane et al., 1999] reported that a 2-D model could predict the bed deformations reasonably well in a curved channel event without the inclusion of a secondary flow correction due to the major role of main flows. However, it is argued by [Kasvi et al., 2013] that the morphodynamics at the inner bank cannot be predicted by a 2-D model with a secondary flow correction. In contrast, the study presented here clearly demonstrates that at a natural bend where secondary flow plays an important role, a 2-D model is capable of predicting the morphodynamics ahead, however it is required that the 2-D model calculates the secondary flow effect and reasonably parameterizes varying grain size. The secondary flow effect has a first priority importance in comparison to other parameters. The well-known factors such as sediment transport formula and roughness height influence the quantification of bed changes but do not alter the feature of morphological changes at the bend. Therefore, the choice of the factors is considered to have less priority during model parameterization.

\section{Conclusions}

This study developed a depth-averaged 2-D nonequilibrium sediment transport model with an inclusion of a secondary flow correction, and the model was tested in two small-scale experiments and a 1 year 
morphodynamic event at a natural bend. A number of parameters potentially influencing the bar formation at the natural bend were evaluated through a series of simulations. Specific conclusions can be drawn:

1. The 2-D nonequilibrium sediment transport model is capable of predicting hydraulics and bed changes at laboratory-scale reasonably well.

2. Secondary flow correction terms in a 2-D model affect bend hydraulics, and thereby also bar formation. Thus the treatment of these terms should be given a priority during morphdynamic modeling at a bend. The turbulent terms are also important for curved channel [Begnudelli et al., 2010].

3. Results indicate that grain-size parameterization has the most significant effects on morphological changes, both in terms of bar size and pattern. Distributed and nonuniform grain parameterization is vital for accurate prediction.

4. The feature of bed changes is hardly affected by choice of sediment transport formulae, thus we consider it has a lower priority during simulation.

5. The roughness parameters have an impact on bed shear stress of a similar order of magnitude within the whole area. This leads to changing bar size but not bar distribution at a bend.

6. A depth-averaged 2-D model could be used with some confidence for modeling channel hydraulics and morphology at a natural bend provided that secondary flow features are corrected and grain-size parameterization are undertaken. Considering the advantages of 2-D models in saving computational time compared to 3-D models, 2-D models would be provide sufficiently reliable simulation of morphodynamics at a natural bend.

7. The annual bar formations at the natural bend were predicted reasonably well by the 2-D model described. This further indicates the capability of 2-D models for simulating morphodynamics at a natural-scale bend.

\section{Acknowledgments}

M.G. is a Research Fellow at the School of Civil Engineering and would like to thank the financial support for his research in the University of Leeds. The Keswick case study data set was provided by the Environment Agency, England. We would like to thank David Brown, Helen Reid, and Peter Spencer for their help in making this data and background information available. Environment Agency data can be requested from Inforequests.cmblnc@environmentagency.gov.uk.

\section{References}

Abad, J. D., G. C. Buscaglia, and M. H. Garcia (2008), 2D stream hydrodynamic, sediment transport and bed morphology model for engineering applications, Hydrol. Processes, 22(10), 1443-1459.

Alho, P., and J. Mäkinen (2010), Hydraulic parameter estimations of a 2D model validated with sedimentological findings in the point bar environment, Hydrol. Processes, 24(18), 2578-2593.

Begnudelli, L., A. Valiani, and B. F. Sanders (2010), A balanced treatment of secondary currents, turbulence and dispersion in a depthintegrated hydrodynamic and bed deformation model for channel bends, Adv. Water Resour., 33(1), 17-33.

Blanckaert, K. (2015), Flow separation at convex banks in open channels, J. Fluid Mech., 779, 432-467.

Bohorquez, P., F. García-García, F. Pérez-Valera, and C. Martínez-Sánchez (2013), Unsteady two-dimensional paleohydraulic reconstruction of extreme floods over the last $4000 \mathrm{yr}$ in Segura River, southeast Spain, J. Hydrol., 477, 229-239.

Bohorquez, P., and C. Ancey (2016), Particle diffusion in non-equilibrium bedload transport simulations, Appl. Math. Modell., 40(17-18), 7474-7492.

Bui, M. D., and P. Rutschmann (2010), Numerical modelling of non-equilibrium graded sediment transport in a curved open channel, Comput. Geosci., 36(6), 792-800.

Cheng, N. (2002), Exponential formula for bedload transport, J. Hydraul. Eng., 128(10), 942-946.

De Vriend, H. J. (1977), A mathematical model of steady flow in curved shallow channels, J. Hydraul. Res., 15(1), 37-54.

De Vriend, H. J., and F. G. Koch (1978), Flow of Water in a Curved Open Channel With A Fixed Uneven Bed, Delft Univ. of Technol., Netherlands.

Duan, J. G., and S. K. Nanda (2006), Two-dimensional depth-averaged model simulation of suspended sediment concentration distribution in a Groyne field, J. Hydrol., 327(3-4), 426-437.

El kadi Abderrezzak, K., and A. Paquier (2009), One-dimensional numerical modeling of sediment transport and bed deformation in open channels, Water Resour. Res., 45, W05404, doi:10.1029/2008WR007134.

Finnie, J., B. Donnell, J. Letter, and R. Bernard (1999), Secondary flow correction for depth-averaged flow calculations, J. Eng. Mech., 125(7), $848-863$.

Fischer-Antze, T., N. R. B. Olsen, and D. Gutknecht (2008), Three-dimensional CFD modeling of morphological bed changes in the Danube River, Water Resour. Res., 44, W09422, doi:10.1029/2007WR006402.

Ghamry, H. K., and P. M. Steffler (2002), Two dimensional vertically averaged and moment equations for rapidly varied flows, J. Hydraul. Res., 40(5), 579-587.

Greimann, B., Y. Lai, and J. C. Huang (2008), Two-dimensional total sediment load model equations, J. Hydraul. Eng., $134(8), 1142-1146$.

Guan, M., N. Wright, and P. Sleigh (2013), A robust 2D shallow water model for solving flow over complex topography using homogenous flux method, Int. J. Numer. Methods Fluids, 73(3), 225-249.

Guan, M., N. Wright, and P. Sleigh (2014), 2D Process based morphodynamic model for flooding by noncohesive dyke breach, J. Hydraul. Eng., 140(7).

Guan, M., N. Wright, and P. Sleigh (2015a), Multimode morphodynamic model for sediment-laden flows and geomorphic impacts, J. Hydraul. Eng., 141(6).

Guan, M., N. G. Wright, P. A. Sleigh, and J. L. Carrivick (2015b), Assessment of hydro-morphodynamic modelling and geomorphological impacts of a sediment-charged Jökulhlaup, at Sólheimajökull, Iceland, J. Hydrol., 530, 336-349.

Guan, M., J. L. Carrivick, N. G. Wright, P. A. Sleigh, and K. E. Staines (2016), Quantifying the combined effects of multiple extreme floods on river channel geometry and on flood hazards, J. Hydrol., 538, 256-268.

Guymer, I. (1998), Longitudinal dispersion in sinuous channel with changes in shape, J. Hydraul. Eng., 124(1), 33-40. 
Iwasaki, T., Shimizu, Y., and Kimura, I. (2016), Numerical simulation of bar and bank erosion in a vegetated floodplain: A case study in the Otofuke River, Adv. Water Resour., 93, 118-134.

Johannesson, H., and G. Parker (1989), Velocity redistribution in meandering rivers, J. Hydraul. Eng., 115(8), 1019-1039.

Kasvi, E., P. Alho, M. Vaaja, H. Hyyppä, and J. Hyyppä (2013), Spatial and temporal distribution of fluvio-morphological processes on a meander point bar during a flood event Hydrol. Res., 44(6), 1022-1039.

Kasvi, E., P. Alho, E. Lotsari, Y. Wang, A. Kukko, H. Hyyppä, and J. Hyyppä (2015), Two-dimensional and three-dimensional computational models in hydrodynamic and morphodynamic reconstructions of a river bend: Sensitivity and functionality, Hydrol. Processes, 29(6), 1604-1629.

Khosronejad, A., C. Rennie, S. Salehi Neyshabouri, and R. Townsend (2007), 3D Numerical modeling of flow and sediment transport in laboratory channel bends, J. Hydraul. Eng., 133(10), 1123-1134.

Lane, S. N. (1998), Hydraulic modelling in hydrology and geomorphology: A review of high resolution approaches, Hydrol. Processes, 12(8), $1131-1150$.

Lane, S. N., K. F. Bradbrook, K. S. Richards, P. A. Biron, and A. G. Roy (1999), The application of computational fluid dynamics to natural river channels: Three-dimensional versus two-dimensional approaches, Geomorphology, 29(1-2), 1-20.

Langendoen, E. J., A. Mendoza, J. D. Abad, P. Tassi, D. Wang, R. Ata, K. El kadi Abderrezzak, and J.-M. Hervouet (2015), Improved numerical modeling of morphodynamics of rivers with steep banks, Adv. Water Resour., 93, 4-14.

Li, S. C., and C. J. Duffy (2011), Fully coupled approach to modeling shallow water flow, sediment transport, and bed evolution in rivers, Water Resour. Res., 47, W03508, doi:10.1029/2010WR009751.

Lien, H., T. Hsieh, J. Yang, and K. Yeh (1999), Bend-flow simulation using 2D depth-averaged model, J. Hydraul. Eng., 125(10), 1097-1108.

Meyer-Peter, E., and R. Müller (1948), Formulas for Bed Load Transport, 39-64 pp., Stockholm, IAHR, Stockholm, Sweden.

Nicholas, A. P. (2013), Modelling the continuum of river channel patterns, Earth Surf. Processes Landforms, 38(10), $1187-1196$

Odgaard, A. (1986), Meander flow model. I: Development, J. Hydraul. Eng., 112(12), 1117-1135.

Odgaard, A., and M. Bergs (1988), Flow processes in a curved alluvial channel, Water Resour. Res., 24(1), 45-56.

Palmsten, M. L., J. L. Kozarek, and J. Calantoni (2015), Video observations of bed form morphodynamics in a meander bend, Water Resour. Res., 51, 7238-7257, doi:10.1002/2014WR016321.

Song, C. G., I. W. Seo, and Y. D. Kim (2012), Analysis of secondary current effect in the modeling of shallow flow in open channels, Adv. Water Resour., 41, 29-48.

Toro, E. F. (2001), Shock-Capturing Methods for Free-Surface Shallow Flows, 326 pp., John Wiley, Wiley, Chichester, U. K.

van Rijn, L. C. (1984), Sediment transport part I, bed load transport, J. Hydraul. Eng., 110(10), 1431-1456.

Verhaar, P. M., P. M. Biron, R. I. Ferguson, and T. B. Hoey (2008), A modified morphodynamic model for investigating the response of rivers to short-term climate change, Geomorphology, 101(4), 674-682.

Wang, D., P. Tassi, K. E. Abderrezzak, A. Mendoza, J. D. Abad, and E. Langendoen (2014), 2D and 3D numerical simulations of morphody namics structures in large-amplitude meanders, in proceedings of River Flow 2014, edited by A. J. Schleiss, et al., pp. 1105-1111, CRC Press, Lausanne, Switzerland.

Waters, K. A., and J. C. Curran (2015), Linking bed morphology changes of two sediment mixtures to sediment transport predictions in unsteady flows, Water Resour. Res., 51, 2724-2741, doi:10.1002/2014WR016083.

Wilcock, P., and J. Crowe (2003), Surface-based transport model for mixed-size sediment, J. Hydraul. Eng., 129(2), 120-128.

Wong, M., and G. Parker (2006), Reanalysis and correction of bed-load relation of Meyer-Peter and Müller using their own database, $J$. Hydraul. Eng., 132(11), 1159-1168.

Wu, W. (2004), Depth-averaged two-dimensional numerical modeling of unsteady flow and nonuniform sediment transport in open channels, J. Hydraul. Eng., 130(10), 1013-1024.

Wu, W., W. Rodi, and T. Wenka (2000), 3D numerical modeling of flow and sediment transport in open channels, J. Hydraul. Eng., 126(1), 4-15.

Wu, W., F. D. Shields, S. J. Bennett, and S. S. Y. Wang (2005), A depth-averaged two-dimensional model for flow, sediment transport, and bed topography in curved channels with riparian vegetation, Water Resour. Res., 41, W03015, doi:10.1029/2004WR003730. 